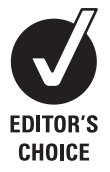

1 Department of Epidemiology, University of Michigan School of Public Health in Ann Arbor, Michigan, USA; ${ }^{2}$ Department of Anthropology, Emory University, Atlanta, Georgia, USA; ${ }^{3}$ Jimma University, Jimma, Ethiopia;

${ }^{4}$ School of Medicine, University of Michigan, Ann Arbor,

Michigan, USA; ${ }^{5}$ Department of Epidemiology, Columbia

University, New York City, New York, USA

Correspondence to:

Dr C Hadley, Department of Anthropology, Emory University, 218D Anthropology Building, 1557 Dickey Drive, Atlanta, GA 30322, USA; chadley@emory. edu

Accepted 13 January 2008

\title{
Food insecurity, stressful life events and symptoms of anxiety and depression in east Africa: evidence from the Gilgel Gibe growth and development study
}

\author{
C Hadley, ${ }^{1,2}$ A Tegegn, ${ }^{3}$ F Tessema, ${ }^{3} \mathrm{~J}$ A Cowan, ${ }^{1,4}$ M Asefa, ${ }^{3}$ S Galea ${ }^{1,5}$
}

\begin{abstract}
Objectives: Common mental disorders are a major contributor to the burden of disease in developing countries. An assessment was carried out of whether food insecurity and exposure to stressful life events, two common features of life in sub-Saharan Africa (SSA), are associated with symptoms of mental disorders among adults.
\end{abstract}

Methods: The Gilgel Gibe Growth and Development Study (GGGDS) is an ongoing cohort study in rural Ethiopia. Participants of the GGGDS were randomly selected from households from a complete census of persons living in the area. The Hopkins Symptom Checklist and the Harvard Trauma Questionnaire were used to assess anxiety and depression and post-traumatic stress symptoms.

Results: Among 902 adult participants, food insecurity, stressful life events and symptoms of common mental disorders were highly prevalent. In separate multivariate models adjusting for potential confounders, food insecurity and stressful life events were independently associated with high symptoms of depression, anxiety and post-traumatic stress.

Conclusions: Potentially modifiable stressors may influence variation in common mental disorders in Ethiopia, and SSA more generally. These findings suggest that the negative effects of food insecurity extend beyond nutritional outcomes and that interventions that promote food security may also positively influence adult mental health in the region.

There is increasing recognition that common mental disorders are a major contributor to the global burden of disease and that the impact of this burden is substantial in developed and developing countries. ${ }^{1}$ Global estimates of the burden of disease suggest that the burden of common mental disorders is similar to, and in many cases greater than, that of many physical health disorders. ${ }^{12}$ It is also increasingly recognised that common mental disorders may have intergenerational consequences. For example, evidence is emerging that chronic psychosocial stress among pregnant women may have deleterious effects on fetal development, and negatively affects selected parenting and caregiving practices. ${ }^{3}$

The recognition of the burden of common mental disorders signals a shift in global public health away from a nearly exclusive focus on infectious diseases and diseases of undernutrition to a broader aim of identifying the causes of poor health. Although there is an abundance of research about the underlying conditions that ultimately lead to common mental disorders in the developed world, far less is known about the determinants of common mental disorders in low-income developing countries. This is a critical gap because identifying the factors that influence common mental disorders and the role that these disorders play in shaping poor overall health may have substantial implications for development of effective interventions in poorer countries. ${ }^{45}$

Food insecurity, defined as insecure access to sufficient food for an active and healthy life, is a massive, but often neglected, public health and human rights concern in many developing countries. $^{67}$ In many regions of sub-Saharan Africa (SSA), more than one-third of households are food insecure. ${ }^{7}$ It is expected that by 2020 the number of people in SSA who will experience severe food insecurity will double. ${ }^{8}$ Public health concern regarding food insecurity often focuses on the nutrition-related consequences of food insecurity, but ethnographic and community-based studies have suggested that the uncertainty and unpredictability that characterise food-insecure households may also promote anxiety and depression. ${ }^{9}{ }^{10}$ These studies either have been qualitative in nature, focused only on women, or have taken place in developed country settings. Furthermore, these conditions may be exacerbated by chronic stressful life events including economic problems and episodic natural and human-made stressors, each of which reinforces and entrenches food insecurity. ${ }^{11}{ }^{12}$ Stressors may include loss of property, displacement, observing or involvement in beatings, and insecure access to healthcare. Commonly experienced stressors also include illness and death, which are highly prevalent in developing country settings such as Ethiopia where the infant mortality rate in rural areas is $127 / 1000$ live births and the maternal mortality ratio is 653 per $100000 .^{13}$ Despite the observation that stressful life events and food insecurity are two highly prevalent features of life in much of the developing world, there has been little research that has considered the role of these potentially modifiable conditions in shaping mental health. ${ }^{25}$

The objective of this study was to examine the association between the experience of food insecurity, stressful life events and low socioeconomic status (SES), and common mental disorders, including depression, anxiety and post-traumatic stress (PTS) in adults living in a rural area in Ethiopia. We hypothesised that food insecurity, exposure to stressful life events and low SES would be independent predictors of symptoms of anxiety, 
depression and PTS among adult men and women living in rural southwest Ethiopia.

\section{METHODS}

\section{Sample}

This study took place in Jimma zone, southwest Ethiopia, in the Gilgel Gibe area outside Jimma Town. This is a primarily rural area where the principal occupation is subsistence agriculture. In the past years large numbers of inhabitants have been affected by the construction of a hydroelectric dam, which disrupted lives and livelihoods and forced many people from their homes and to relocate to nearby towns and villages.

The Gilgel Gibe Growth and Development Study (GGGDS) is a cohort study of families in the Gilgel Gibe region that is concerned with adult mental health and child development. The study involves questionnaire and anthropometric information collected from the parents, and developmental assessments conducted on their children. We report here on baseline information collected from the parents.

Jimma University conducts ongoing complete demographic surveillance in the Gilgel Gibe area that is used to collect vital data for a complete census of the population of some 8000 households in the Gilgel Gibe area. Records are updated multiple times each year and there are high levels of support from the community so refusals are rare. The cohort baseline for the GGGDS was a random sample of households that had a child between the ages of 3 and 24 months from the universe of all births in Gilgel Gibe in the 2 years prior to the estimated start date of the survey ( 2000 births). We sampled 550 households at baseline. From these, 79 households were not included because the children were unable to be located, had died or had moved from the study area. An additional 20 households were excluded because the father was not living in the household or could not be located. Thus, the overall response rate was $82 \%$. Data were collected between December 2006 and January 2007.

A structured questionnaire was developed and administered to participants by 10 interviewers. Questionnaires and consent documents were developed in English then translated and back translated into the two dominant languages in the study areaAmharic and Affan Oromifa-by native speakers. Interviewers underwent a week-long training period that included cognitive interviewing, practice interviewing and role playing. Tests were periodically administered throughout the week to assess knowledge of the questionnaire. Following the training, interviewers undertook a pilot study. Pilot data were also checked for consistency, outliers and missing values. After the pilot, interviewers and investigators met to discuss experiences and issues and to finalise questionnaires. Upon finalising the questionnaire, households were visited and all participants were interviewed in their house in a private area. Husbands and wives were interviewed separately using questionnaires developed specifically for men and women. Written informed consent was obtained from all participants. The Institutional Review Boards of the University of Michigan and Jimma University reviewed and approved the study protocol.

\section{Survey domains}

Household level food insecurity was measured with a sevenitem scale based on those used and validated previously in diverse settings in developing countries. ${ }^{14-16}$ Women and men were separately asked whether because food ran out or money was not enough to buy food, in the last 3 months, they: (1) worried about running out of food, (2) ran out of food, (3) reduced the variety of food for their children, (4) did not have enough food to give their children to eat, (5) or the other adult did not eat enough, (6) spent the whole day without food, and (7) or anyone else in the household had ever had to ask others for food or money to buy food. These items were scored as yes/ no and analysis showed that the scale had high internal consistency (Cronbach's alpha 0.93), so responses of the husband and wife were summed. Maternal and paternal summed scores were also highly correlated $(p<0.001)$, so the average was taken to represent the household's food insecurity situation. This score was initially divided into low, medium and high levels of food insecurity, but analyses revealed no differences between the low and medium food-insecure categories. We therefore coded the food security variable into a dichotomous variable with a value of 1 indicating food security and a value of zero indicating food insecurity.

The Harvard Trauma Questionnaire (HTQ) was used to measure exposure to stressful life events over the course of an individual's life. The HTO consists of a list of 40 stressful life events and 16 items used to categorised individuals as experiencing PTS disorder, and has been used widely in developing country settings. ${ }^{17}{ }^{18}$ The stressful life events scale asks whether the respondent has ever experienced 40 different life events. We modified the instrument slightly to make it more locally appropriate by removing three items that were not culturally appropriate for men. We added one item, marriage by abduction, for women as this has been reported in rural Ethiopia. The total number of stressful life events experienced by each respondent was calculated; this was used in a continuous and dichotomous fashion (see below).

Household SES was measured using three different indicators. First, a set of material assets was asked of each household. Items were summed and households' SES was categorised based on whether the household was above or below the median asset ownership. The second indicator of household SES was based on animal and livestock ownership; a summary score was created and households below the median level of ownership were categorised as having low livestock ownership. Men also provided a subjective measure of household SES by responding to a pictorial scale. This scale, called the ladder, presents respondents with a picture of a ladder and they are asked to place themselves on the ladder relative to those in their community who have the most and those who have the least. ${ }^{19}$ Interviewers reported that respondents immediately grasped the concept of the ladder. Women provided corresponding responses to some of the material items and these were highly associated with their partner's responses. We therefore used the men's responses as estimates of the household SES. Measures of SES were dichotomised because there was less variation than we had anticipated; we had originally planned to include other measures such as household attributes but these show very little variation (table 1).

Additional control variables included were age (years), gender and body mass index (BMI). BMI was dichotomised into greater than or equal to 18.5 and less than 18.5, which is considered indicative of chronic energy deficiency (CED) ${ }^{20}$ Information on educational status was not collected since it is known to be very low in the study population.

\section{Key dependent variables}

The Hopkins Symptom Checklist-25 (HSCL) was used to assess maternal and paternal symptoms of anxiety and depression. The HSCL is an inventory of anxiety (10 items) and depressive symptoms (15 items) and has been used and validated in a range 
Table 1 Household characteristics of baseline participants in the Gilgel Gibe Growth and Development Study ( $n=451$ households)

\begin{tabular}{|c|c|c|}
\hline Household variables* & Mean (SD) & Percentage \\
\hline $\begin{array}{l}\text { SES ladder (min } 0 \text {, max } 10 \text { higher levels indicate higher } \\
\text { SES) }\end{array}$ & $2.9(1.3)$ & \\
\hline $\begin{array}{l}\text { Food-insecure score ( } \min 1, \max 7 \text { higher score indicates } \\
\text { greater insecurity) }\end{array}$ & $2.8(2.8)$ & \\
\hline Food secure (summed food-insecure score $\leqslant 4$ ) & & 66 \\
\hline \multicolumn{3}{|l|}{ House floor material } \\
\hline Earthen & & 98 \\
\hline Other & & 2 \\
\hline \multicolumn{3}{|l|}{ House roof material } \\
\hline Thatched & & 79 \\
\hline Other & & 21 \\
\hline \multicolumn{3}{|l|}{ Wall material } \\
\hline Mud & & 98 \\
\hline Other & & 2 \\
\hline \multicolumn{3}{|l|}{ Source of drinking water } \\
\hline Unprotected well or spring & & 54 \\
\hline Protected well or spring & & 16 \\
\hline River & & 22 \\
\hline Piped & & 9 \\
\hline \multicolumn{3}{|l|}{ Toilet facility } \\
\hline Private toilet or public toilet facility & & 59 \\
\hline Open area used as toilet facility & & 40 \\
\hline
\end{tabular}

${ }^{*}$ Mean and standard deviation shown unless otherwise indicated. SES, socioeconomic status.

of culturally and economically diverse settings. ${ }^{18} 2122$ The instrument has been used extensively in vulnerable populations, such as refugees and war survivors, and in a range of crosscultural contexts including East Africa. ${ }^{18}{ }^{22} 23$ For each item, respondents were asked to identify whether they had experienced the item and the severity of the symptom on a four-point Likert scale in the 2 weeks prior to the survey. These include statements such as "In the past week how bothered have you been by your heart pounding or racing?" and "In the past week how bothered were you by feeling low in energy, slowed down?" Using the scoring strategies previously employed by others, ${ }^{24-27}$ we calculated three variables from the HSCL. First, we calculated the average item score by summing across all items and dividing by 25. Respondents with an average item score over 1.75 were categorised as distressed. We used the same procedure and summed across the first 10 items to create a measure of high symptoms of anxiety and summed across the remaining 15 items to obtain a measure of high symptoms of depression. The HSCL is not a diagnostic tool, but we assume that higher scores are indicative of greater likelihood of having a common mental disorder.

PTS symptoms were assessed using a 16-item HTQ inventory based on the Diagnostic and statistical manual of mental disorders, 4 thedition (DSM-IV) post-traumatic stress disorder criteria. Items were assessed with a four-point Likert scale and items were summed across the 16-item scale. For the purpose of this analysis we summed PTS responses in the Likert scale, and divided the sum by 16 , the total number of items. There are two commonly used cut-offs for determining whether a participant is "checklist positive" for PTS; these are 2.0 and 2.5. Although 2.5 was originally used as a cut-off, more recent studies suggest that 2.0 may be more reasonable. ${ }^{18}$ In this paper we use the 2.0 cut-off.

\section{Statistical methods}

Univariate statistics were used to describe the sample, the prevalence and distribution of key independent variables, and to report the prevalence of anxiety and depression and PTS. Bivariate tests, namely the $\chi^{2}$ test and the Spearman's correlation, were used to assess the associations between hypothesised predictor variables and the dependent variables of interest. Generalised estimating equations (GEEs) were used to separately model the relations among food insecurity, exposure to stressful life events, SES and the three mental health indicators while controlling for potentially confounding variables. GEE models account for the possible non-independence between respondents given the sampling design whereby husband and wife were living in the same household. The criterion for statistical significance was set at 0.05 . All statistical tests were carried out in SAS V.9.1.

\section{RESULTS}

Complete data were available for 902 individuals (ie, 451 husband-wife pairs) for analyses. As indicated by features of the respondents' homes, poverty is endemic in the study area (table 1). For example, a majority (98\%) of the homes had earthen floors, thatched roofs (79\%), and mud walls (98\%). Most respondents received their drinking water from unprotected wells or springs, with only $9 \%$ having direct access to piped water. Fewer than two-thirds of homes had access to private or public latrines and $40 \%$ were relying on open air "facilities". Men and women reported high levels of food insecurity. Mean scores for men were 2.7 items and 2.9 for women (maximum of 7, endorsing all food-insecurity items); this difference was not significant $(p=0.32)$. Scores were also correlated $(p<0.001)$ and showed high agreement $($ kappa $=0.72)$, further suggesting that both measures serve as an indicator of household food insecurity status.

The three measures of household SES were correlated with one another $(p<0.01)$ and with household food insecurity. Food-insecure households were more likely to be in the lowlivestock category $(p=0.04)$, the low-material goods category $(p<0.01)$ and to have a lower score on the ladder $(p<0.01)$.

Men were on average older than their wives (mean age 33.5 years vs 26.1 years, $p<0.01$; table 2 ). Men had an average BMI of 19 (standard deviation (SD) 2.1), which was lower than the average BMI of women (19.4, SD 2.1; $p<0.01)$; a difference consistent with other studies in Ethiopia. ${ }^{28}$ More than one-third of respondents had a BMI less than 18.5, which is an internationally recognised indicator of chronic energy deficiency, and men were more likely to have a BMI less than 18.5 than were women. ${ }^{20}$

From a possible 37 stressful life events, men experienced on average 5.7 events (SD 3.54). Out of a possible 40 items, women experienced on average 2.9 (SD 2.17; $\mathrm{p}<0.01$ ). After accounting for the difference in the total number of items that men and women could answer, the gender difference remained significantly different $(p<0.01)$. The five most commonly endorsed items for men were witnessing beatings to the head or body $(72 \%)$, imprisonment $(53 \%)$, confiscation or destruction of property (53\%), beating to the body (49\%) and lack of food and water $(36 \%)$. For women, the five most commonly endorsed items were witnessing beatings to the head or body $(48 \%)$, confiscation or destruction of personal property $(39 \%)$, beatings to the body $(31 \%)$, lack of food or water $(25 \%)$ and lack of healthcare when it was needed (19\%). Interestingly, 15 items were endorsed by more than $10 \%$ of men whereas only 10 items were endorsed by more than $10 \%$ of women. For the most part there was a high degree of overlap in stressors experienced by men and women. Of those endorsed by at least $10 \%$ of women, nine were also endorsed by at least $10 \%$ of men (sexual abuse 
was not mentioned by men, but was mentioned by women). Men, however, differentially nominated items related to forced separation from family, imprisonment and forced labour.

Women (42\%) were more likely than men (37\%) to be categorised as distressed, but this difference was not statistically significant ( $p=0.08$; table 2$)$. Just over $42 \%$ of respondents had an anxiety score greater than the 1.75 cut-off, and $36 \%$ had a depression score above the 1.75 cut-off. Women were more likely than men to have an elevated anxiety score (47\% vs $37 \%$; $\mathrm{p}<0.01)$. There was no difference between the sexes in the prevalence of high depressive symptoms (37\% women vs 35\% of men; $p=0.49)$. Using the 2.0 cut-off, $19 \%$ of respondents were classified with high PTS symptoms $(20 \%$ of men and $17 \%$ of women; $p=0.2$ ).

Distress, high symptoms of anxiety, depression and PTS were associated with adult nutritional status, SES, stressful life events and food insecurity (table 3). Individuals with a low BMI were more likely to be categorised as distressed and to have high symptoms of anxiety, high symptoms of depression and high PTS. There was no difference in the prevalence of distress $(p=0.22)$ or high symptoms of anxiety $(p=0.49)$ across different levels of material wealth, but $40 \%$ of individuals in homes with low material goods had high depressive symptoms compared with $32 \%$ in households with high material goods $(p=0.01)$. High material goods were also associated with lower PTS $(p=0.04)$. Among households with high livestock holdings, $45 \%$ of individuals were distressed, whereas distress was observed among 37\% of individuals in low-livestock holding households $(p=0.02)$ but livestock holdings were not associated with the other outcomes. Finally, individuals categorised as distressed $(p<0.01)$, having high anxiety $(p<0.01)$, having high depressive symptoms $(p<0.001)$ and having PTS $(p<0.001)$ scored lower on the SES ladder.

Household food-insecurity status and exposure to stressful life events was associated with distress, high symptoms of anxiety, high symptoms of depression and high PTS. In foodinsecure households, $65 \%$ respondents were distressed compared with $34 \%$ in food-secure households $(p<0.01)$. High symptoms of depression (62\%) and anxiety (65\%) were also more common in food-insecure households than in food-secure homes $(27 \%$ and $34 \%$, respectively; $\mathrm{p}<0.01)$. PTS was also more prevalent among those in food-insecure households $(p<0.01)$. Exposure to stressful life events was associated with the overall measure of distress and with high symptoms of anxiety and depression and PTS. Those in the distressed group were exposed to 5.2 (SD 3.3) events compared with 3.7 (SD 3.1; p<0.01) among the nondistressed group. Similarly large differences emerged when comparing trauma exposure among those in the high anxiety symptoms $(p<0.01)$ and high depression symptoms groups $(p<0.01)$. Among those who had experienced high levels of stressful events, 35\% were categorised into the high PTS group compared with $9 \%$ who had experienced low levels of stressful life events $(p<0.01)$. Indeed, persons with PTS had experienced on average 6.5 stressful life events (SD 3.6) whereas those without PTS had experienced 3.7 events (SD 2.9; $\mathrm{p}<0.01$ ).

In the multivariable models (table 4), food insecurity, exposure to stressful life events and low SES remained independent predictors of high symptoms of anxiety, depression, PTS and distress independently of one another and potential confounders. Across all outcomes, individuals in food-insecure households were more likely to have symptoms indicative of a common mental disorder. Similarly, also across all outcomes, greater exposure to stressful life events was associated with a greater likelihood of high symptoms of common mental disorders. High perceived SES, as measured by the ladder, was broadly protective against mental health symptoms, although to a lesser extent for PTS. High livestock holdings were predictive of distress but the other measures of material wealth was not. Chronic energy deficiency (ie, low BMI) was associated with high symptoms of anxiety, depression and distress, and there was a trend for those with PTS to have low BMI $(p=0.1)$. Women were also more likely to have high symptoms of all common mental disorders studied.

\section{DISCUSSION}

Using data from a population-based representative sample of households in a rural area of Ethiopia we found that food insecurity, exposure to stressful life events and low SES were associated with high symptoms of common mental disorders.

There are several limitations that should be considered in interpreting this work. We are not aware of prior work validating the HSCL and the HTO in rural Ethiopian populations. Therefore, no inference can be drawn about psychiatric diagnoses in this population. However, the HSCL and the HTQ have been used widely in different cultures and contexts. ${ }^{18}$ Another limitation of this study is that the cross-sectional analysis limits inference about directionality of association between exposure to measures of deprivation and stressful events and exposure to measures of psychiatric function. Therefore, it is possible that persons with a priori mental illness

Table 2 Selected characteristics of study participants $\left(n_{\text {men }}=451, n_{\text {women }}=451\right)$

\begin{tabular}{lccc}
\hline & Men* & Women $^{*}$ & p Value \\
\hline Age, years & $33.4(8.4)$ & $26(5.5)$ & $<0.01$ \\
Height, $\mathrm{cm}$ & $169.7(7.0)$ & $157.0(8.2)$ & $<0.01$ \\
Weight, $\mathrm{kg}$ & $54.8(6.9)$ & $47.8(6.2)$ & $<0.01$ \\
BMI $(\mathrm{kg} /(\mathrm{m} \times \mathrm{m}))$ & $19.0(2.1)$ & $19.4(2.1)$ & $<0.02$ \\
Low BMl $(<18.5)$ & $43 \%$ & $33 \%$ & $<0.01$ \\
Trauma exposure, no. events ever exposed & $5.7(3.5)$ & $3(2.2)$ & $<0.01$ \\
High symptoms of anxiety $\dagger$ & $37 \%$ & $47 \%$ & $<0.01$ \\
High symptoms of depression $\dagger$ & $35 \%$ & $37 \%$ & 0.49 \\
Distress & $37 \%$ & $42 \%$ & 0.08 \\
PTS§ & $21 \%$ & $17 \%$ & 0.21 \\
\hline
\end{tabular}

\footnotetext{
* Mean and standard deviation shown, unless otherwise indicated.

$\uparrow$ Assessed as mean score of items $1-10$ on the HSCL $\geqslant 1.75$.

\#Assessed as mean score of items $11-25$ on the HSCL $\geqslant 1.75$.

-Assessed as HSCL $\geqslant 1.75$.

$\S$ Assessed as HTO $\geqslant 2.0$.

BMI, body mass index; PTS, post-traumatic stress.
} 
Table 3 Bivariate associations between predictor variables and elevated symptoms of anxiety, depression, distress and post-traumatic stress $(n=902)$

\begin{tabular}{|c|c|c|c|c|}
\hline & $\begin{array}{l}\text { High anxiety } \\
\text { symptoms }(\%)^{*}\end{array}$ & $\begin{array}{l}\text { High depression } \\
\text { symptoms }(\%) \dagger\end{array}$ & Distress $(\%)$ & PTS $(\%) \uparrow$ \\
\hline $\mathrm{BMI} \geqslant 18.5$ & 37.9 & 31.8 & 34.9 & 15.8 \\
\hline $\mathrm{BMI}<18.5$ & 48.5 & 43.1 & 46.5 & 24.6 \\
\hline $\mathrm{p}$ value§ & 0.0017 & $<0.001$ & $<0.001$ & 0.0012 \\
\hline High goods & 40.9 & 32.4 & 37.4 & 16.6 \\
\hline Low goods & 43.2 & 40.4 & 41.6 & 22.1 \\
\hline $\mathrm{p}$ value§ & 0.49 & 0.012 & 0.20 & 0.037 \\
\hline High livestock & 46.1 & 39.7 & 45.7 & 20.7 \\
\hline Low livestock & 40.6 & 34.9 & 37.2 & 18.7 \\
\hline $\mathrm{p}$ value§ & 0.14 & 0.19 & 0.022 & 0.49 \\
\hline High ladder & 36.5 & 30.5 & 32.4 & 15 \\
\hline Low ladder & 49.2 & 43.6 & 48.5 & 24.6 \\
\hline $\mathrm{p}$ value§ & $<0.001$ & $<0.001$ & $<0.001$ & $<0.001$ \\
\hline Food secure & 33.6 & 27.6 & 30.9 & 14.9 \\
\hline Food insecure & 58.5 & 52.9 & 55.9 & 27.6 \\
\hline $\mathrm{p}$ value§ & $<0.001$ & $<0.001$ & $<0.001$ & $<0.001$ \\
\hline Low trauma exposure & 33.5 & 26.5 & 30.3 & 9.0 \\
\hline High trauma exposure & 55.6 & 51.6 & 53.9 & 35.5 \\
\hline $\mathrm{p}$ value§ & $<0.001$ & $<0.001$ & $<0.001$ & $<0.001$ \\
\hline
\end{tabular}

*Assessed as mean score of items $1-10$ on the HSCL $\geqslant 1.75$.

$\nmid$ Assessed as mean score of items $11-25$ on the HSCL $\geqslant 1.75$.

Assessed as mean score on the HSCL $\geqslant 1.75$.

-Assessed as mean score on the HTQ $\geqslant 2.0$.

$\S \chi^{2}$ test.

BMI, body mass index; PTS, post-traumatic stress.

are less likely to achieve food security or are exposed to more stressful life events as a result of their mental illness. However, somewhat mitigating this concern is that longitudinal studies in developed world settings have shown that individuals who become food insufficient are more likely to develop symptoms of common mental disorders; ${ }^{29}$ our observations here suggest a comparable pattern in a developing world setting. It is possible too that because we sampled households with children our results do not extend to households without children. A final consideration is our use of the stressor scale: we summed across all stressful events, an approach that was selected given that we were primarily concerned with a cumulative measure of life stress. It is likely that some of these events are more damaging to mental heath than others, and perhaps should have been weighted as such. However, lacking contextual information on how these events are perceived and when they occurred in the life course, we elected to pursue the more conservative approach that we have taken. A more appropriate approach would be to elicit stressors and weights from the study communities; we hope to do this in a future survey.

Strengths of the study include the use of a representative sample of the study area, the separate interviewing of men and women, and the inclusion of a wide array of covariates. The measures of SES were all interrelated and associated with food insecurity, which is expected given that more resources are assumed to offer protection against periods of food insecurity and moderate the impact of various negative stressors. Also, even though the SES ladder was answered only by men, it still was strongly associated with maternal mental health symptoms. Further, women's responses to questions on household SES were all highly associated with their spouses' responses; these associations speak to our ability to properly characterise the household's socioeconomic status.

The finding that food insecurity is associated with indicators of common mental disorders is consistent with studies from developed countries, ${ }^{30-32}$ and from other smaller studies carried

Table 4 Multivariate generalised estimating equation models predicting common mental disorders $(\mathrm{n}=902)$

\begin{tabular}{|c|c|c|c|c|c|c|c|c|}
\hline \multirow[b]{2}{*}{ Variable } & \multicolumn{2}{|c|}{ High anxiety symptoms* } & \multicolumn{2}{|c|}{ High depression symptoms $\dagger$} & \multicolumn{2}{|c|}{ Distress } & \multicolumn{2}{|l|}{ PTS } \\
\hline & B & p Value & B & p Value & B & p Value & B & p Value \\
\hline Food secure & -1.04 & $<0.01$ & -1.22 & $<0.01$ & -1.14 & $<0.01$ & -0.63 & $<0.01$ \\
\hline Stressful life events & 0.14 & $<0.01$ & 0.15 & $<0.01$ & 0.14 & $<0.01$ & 0.26 & $<0.001$ \\
\hline High SES ladder & -0.23 & 0.01 & -0.18 & 0.01 & -0.24 & $<0.01$ & -0.2 & 0.06 \\
\hline Female & 0.95 & $<0.01$ & 0.71 & $<0.01$ & 0.8 & $<0.01$ & 0.76 & $<0.01$ \\
\hline $\mathrm{BMI}<18.5$ & 0.32 & 0.03 & 0.32 & 0.03 & 0.33 & 0.03 & 0.29 & 0.10 \\
\hline High goods & 0.13 & 0.42 & -0.18 & 0.30 & 0.03 & 0.88 & -0.23 & 0.29 \\
\hline High livestock & 0.33 & 0.08 & 0.35 & 0.07 & 0.52 & $<0.01$ & 0.21 & 0.42 \\
\hline Age & 0.01 & 0.50 & 0.01 & 0.19 & 0.01 & 0.32 & 0.02 & 0.29 \\
\hline
\end{tabular}

${ }^{*}$ Assessed as mean score of items $1-10$ on the $\mathrm{HSCL} \geqslant 1.75$

$\uparrow$ Assessed as mean score of items $11-25$ on the HSCL $\geqslant 1.75$.

\#Assessed as mean score on the HSCL $\geqslant 1.75$.

-Assessed as mean score on the HTO $\geqslant 2.0$.

BMI, body mass index; PTS, post-traumatic stress; SES, socioeconomic status. 
out in other SSA countries, and has resounding implications for population health given the prevalence of food insecurity in the world. Hunger is commonly reported as the most pressing concern among rural East Africans. A study of psychosocial stress among 45 women from northern Kenya found that hunger was the most commonly reported "daily bother" followed by a list of other traumatic events including armed cattle raiding (eg, theft), illness and frequent movement (ie, displacement). ${ }^{10}$ Also, in a free listing exercise in a study of two ethnic groups of women in Tanzania, "hunger" was reported as one of the most stressful daily occurrences. ${ }^{23}$ Mothers among one of the ethnic groups $(n=67)$ reported hunger as the most pressing concern, while hunger was the second most nominated item among the other ethnic group $(n=49)$. Food availability has also emerged as the most salient stressor in a study of several East African pastoralist communities..$^{33}$ Following up on these qualitative studies, Hadley and Patil ${ }^{9}$ showed that food insecurity was associated with symptoms of anxiety and depression in two Tanzanian communities ( $n=449$ mothers). The study reported here confirms and extends these findings. Collectively, the findings are particularly relevant in the SSA context because $33 \%$ of people living in SSA are undernourished, a widely used indicator of food insecurity. Unlike many other parts of the world, the persistent food insecurity experienced in SSA is expected to increase in the coming decades. ${ }^{34}{ }^{35}$ Results such as ours, and those from developed counties, suggest that the population health consequences of food insecurity extend beyond undernutrition and very probably include common mental disorders as well. These results should help draw attention to the importance of food insecurity as a determinant of population health and bolster attempts to raise awareness of the importance of the right to food. ${ }^{36}$ Future research studies should examine the extent to which food insecurity affects mental health through dietary intake or through infusing uncertainty and unpredictability into household environments.

Our results also call attention to the high prevalence of exposure to stressful life events and the possible impact of that exposure on health and well-being even in non-conflict settings; something that has been well studied in developed countries. ${ }^{37}$ Although world attention focuses on SSA intermittently when there are mass traumas such as the complex humanitarian emergencies of west Africa and Sudan or the recent "natural" disasters such as the East African floods which led to the displacement of an estimated 122500 people in Ethiopia alone, the vast majority of the stressful life events studied here are not associated with acute disasters but rather reflect the daily stressors of life in SSA. For example, two of the most commonly reported stressors among men and women were witnessing beatings and destruction of property. Given other known data on intimate partner violence, these data are not surprising and suggest potential underreporting in our study. Garcia-Moreno and colleagues ${ }^{38}$ report in their study of Ethiopia that more than $70 \%$ of women have experienced physical or sexual abuse by a partner. We also report a high rate of imprisonment among men in these communities (but not women). This is probably due to the fact that farmers in the study area can be held in detention if they do not pay the taxation on their land or pay for fertilisers. Consistent with other studies, these stressors appear to contribute to an astonishingly high prevalence of common mental disorders in the context of an area where there is no formal active conflict. ${ }^{4}$ The data presented here are a sobering reflection on the challenges of life in some of the poorer parts of the world and the relation of these daily challenges to mental and physical health and functioning.

\section{What is already known on this subject}

There is an abundance of research about the underlying conditions that promote common mental disorders in the developed world but far less is known about the determinants of common mental disorders in low-income developing countries. Specifically, although stressful life events and food insecurity are two highly prevalent features of life in much of the developing world, there has been little research that has considered the role of these potentially modifiable conditions in shaping mental health.

\section{What this study adds}

This study shows that potentially modifiable stressors may influence symptoms of common mental disorders in sub-Saharan Africa. Specifically, food insecurity and stressful life events were independently associated with high symptoms of depression, anxiety and post-traumatic stress symptoms. These findings suggest that secure access to food has health impacts that extend beyond nutritional outcomes, and offer suggestions for intervention strategies aimed at improving population mental health.

\section{Policy implications}

Results such as ours suggest that the population health consequences of food insecurity extend beyond undernutrition and very likely include common mental disorders as well. These results should help draw attention to the importance of food insecurity as a determinant of population health and bolster attempts to raise awareness of the importance of the right to food.

The results of this study suggest that widespread food insecurity and stressful life events probably have more damaging effects on human performance in SSA than previously believed. Previous work has tended to focus on the nutritional aspects of food insecurity and on the acute, but temporary, influence of conflict. Our work suggests otherwise. Separate and apart from their influence on adult health, there is growing evidence which suggests that anxiety and depression influence children's health and well-being as well. ${ }^{39}$ Maternal psychosocial stress has been linked with preterm delivery and behavioural problems. For example, Patel and collaborators ${ }^{40}$ documented a consistent and robust relationship between maternal mental health (anxiety and depression) and birth outcomes in a cohort study of children born in Goa, India. More generally, our results highlight the important role of political, economic or macrosocial stressors on individual health and well-being. We refer to these as macrosocial in the sense that, although they are experienced at the individual level, the more distal causes are outside the direct influence of the affected individuals. This is a point that has been made by others. ${ }^{41-43}$ Certainty in land tenure, assistance during crises, investment in rural agriculture and internal peace are just a few of the macrolevel determinates of food insecurity and trauma. Future research should attempt 
to more closely link these levels and elucidate the pathways through which individuals are affected.

Acknowledgements: We thank the Robert Wood Johnson Foundation Health and Society Scholars Program. We also thank Vikram Patel, Lia Fernald and one anonymous reviewer for very helpful comments.

Funding: This study was supported in part by a grant from the National Institutes of Health (HD047861) and grants from the Robert Wood Johnson Foundation Health and Society Scholars Program.

Competing interests: None.

Ethics approval: Ethics approval was obtained.

\section{REFERENCES}

1. Murray CJ, Lopez AD. Global mortality, disability, and the contribution of risk factors: Global Burden of Disease Study. Lancet 1997:349:1436-42.

2. World Health Organization. The world health report. Mental health: new understandings, new hope. Geneva: WHO, 2001.

3. McLearn KT, Minkovitz CS, Strobino DM, et al. The timing of maternal depressive symptoms and mothers' parenting practices with young children: implications for pediatric practice. Pediatrics 2006;118:e174-82.

4. Patel V, Flisher A, Cohen A. Mental health. In: Merson MH, Black RE, Mills AJ, eds. International public health: diseases, programs, systems, and policies. Gaithersburg, MD: Aspen Publishers, 2006:355-92.

5. Patel V, Kleinman A. Poverty and common mental disorders in developing countries. Bull World Health Organ 2003;81:609-15.

6. Benson T. Africa's food and nutrition situation: where are we and how did we get here? 2020 Discussion Paper. Washington, DC: The International Food Policy Research Institute, 2004.

7. Food and Agriculture Organization. The state of food insecurity in the world. Rome: FAO, 2005.

8. Wiebe K, Ballenger N, Pinstrup-Andersen P, eds. Who will be fed in the 21st century? Challenges for science and policy. Baltimore, MD: Johns Hopkins University Press, 2001.

9. Hadley C, Patil CL. Food insecurity in rural Tanzania is associated with maternal anxiety and depression. Am J Hum Biol 2006;18:359-68.

10. Pike I. The biosocial consequences of life on the run: a case study from Turkana District, Kenya. Hum Organ 2004:63:221-35.

11. Messer E, Cohen M, Marchione T. Conflict: a cause and effect of hunger. Environmental Change and Security Project Report. Washington, DC: Woodrow Wilson International Center for Scholars, Smithsonian Institution, 2001.

12. Patel V, Araya R, de Lima M, et al. Women, poverty and common mental disorders in four restructuring societies. Soc Sci Med 1999;49:1461-71.

13. Central Statistical Authority and ORC Macro. Ethiopia Demographic and Health Survey 2005. Addis Ababa, Ethiopia, and Calverton, MD: Central Statistical Authority and ORC Macro, 2006.

14. Swindale A, Bilinsky P. Development of a universally applicable household food insecurity measurement tool: process, current status, and outstanding issues. J Nutr 2006;136:1449S-52S

15. Melgar-Quinonez HR, Zubieta AC, MkNelly B, et al. Household food insecurity and food expenditure in Bolivia, Burkina Faso, and the Philippines. J Nutr 2006;136:1431S-7S.

16. Frongillo EA, Nanama S. Development and validation of an experience-based measure of household food insecurity within and across seasons in northern Burkina Faso. J Nutr 2006;136:1409S-19S.

17. Mollica RF, Caspi-Yavin Y, Bollini P, et al. The Harvard Trauma Questionnaire. Validating a cross-cultural instrument for measuring torture, trauma, and posttraumatic stress disorder in Indochinese refugees. J Nerv Ment Dis 1992;180:111-6.

18. Mollica RF, McDonald L, Massagli M, et al. Measuring trauma, measuring torture. Instructions and guidance on the utilization of the Harvard Program in Refugee Trauma's versions of the Hopkins Symptom Checklist-25 (HSCL-25) and the Harvard Trauma Questionnaire (HTQ). Cambridge: Harvard Program in Refugee Studies, 2004.

19. Goodman E, Adler NE, Daniels SR, et al. Impact of objective and subjective social status on obesity in a biracial cohort of adolescents. Obes Res 2003;11:1018-26.
20. Ferro-Luzzi A, Sette S, Franklin M, et al. A simplified approach of assessing adult chronic energy deficiency. Eur J Clin Nutr 1992;46:173-86.

21. Derogatis LR, Lipman RS, Rickels K, et al. The Hopkins Symptom Checklist (HSCL). A measure of primary symptom dimensions. Mod Probl Pharmacopsychiatry 1974;7:79-110.

22. Kaaya SF, Fawzi MC, Mbwambo JK, et al. Validity of the Hopkins Symptom Checklist-25 amongst HIV-positive pregnant women in Tanzania. Acta Psychiatr Scand 2002;106:9-19.

23. Pike I, Patil C. Understanding women's burdens: preliminary findings on psychosocial health among Datoga and Iraqw women of northern Tanzania. Cult Med Psychiatry 2006;30:299-330.

24. Porter M, Haslam N. Predisplacement and postdisplacement factors associated with mental health of refugees and internally displaced persons: a meta-analysis. JAMA 2005;294:602-12

25. Foss GF, Chantal AW, Hendrickson S. Maternal depression and anxiety and infant development: a comparison of foreign-born and native-born mothers. Public Health Nurs 2004;21:237-46.

26. Mathiesen KS, Tambs K, Dalgard OS. The influence of social class, strain and social support on symptoms of anxiety and depression in mothers of toddlers. Soc Psychiatry Psychiatr Epidemiol 1999;34:61-72.

27. Thapa SB, Hauff E. Psychological distress among displaced persons during an armed conflict in Nepal. Soc Psychiatry Psychiatr Epidemiol 2005;40:672-9.

28. Ferro-Luzzi A, International Food Policy Research Institute. Seasonal undernutrition in rural Ethiopia: magnitude, correlates, and functional significance. Washington, DC and Rome: International Food Policy Research Institute and Isituto Nazionale della Nutrizione in collaboration with the Ethiopian Health and Nutrition Research Institute Addis Ababa, 2001.

29. Siefert K, Heflin CM, Corcoran ME, et al. Food insufficiency and physical and mental health in a longitudinal survey of welfare recipients. J Health Soc Behav 2004:45:171-86.

30. Whitaker RC, Phillips SM, Orzol SM. Food insecurity and the risks of depression and anxiety in mothers and behavior problems in their preschool-aged children. Pediatrics 2006;118:e859-68.

31. Bronte-Tinkew J, Zaslow M, Capps R, et al. Food insecurity works through depression, parenting, and infant feeding to influence overweight and health in toddlers. J Nutr 2007:137:2160-5.

32. Laraia BA, Siega-Riz AM, Gundersen C, et al. Psychosocial factors and socioeconomic indicators are associated with household food insecurity among pregnant women. J Nutr 2006;136:177-82.

33. Smith K, Barrett CB, Box PW. Participatory risk mapping for targeting research and assistance: with an example from East African pastoralists. World Dev 2000;28:1945.

34. Pinstrip-Andersen $\mathbf{P}$, Pandya-Lorch R. Meeting food needs in the 21st century: how many and who will be at risk? In: Wiebe K, Ballenger N, Pinstrup-Andersen P, eds. Who will be fed in the 21st century? Challenges for science and policy. Baltimore, MD: Johns Hopkins University Press, 2001:3-16.

35. Baro M, Deubel T. Persistent hunger: perspectives on vulnerability, famine, and food security in sub-Sahara Africa. Annu Rev Anthropol 2006;35:521-38.

36. McClain-Nhlapo C. Implementing a human rights approach to food security. In: The International Food Policy Research Institute, ed. 2020 Vision. Washington, DC: IFPRI, 2004.

37. Kessler RC. The effects of stressful life events on depression. Annu Rev Psychol 1997; 48:191-214

38. Garcia-Moreno C, Jansen HA, Ellsberg M, et al. Prevalence of intimate partne violence: findings from the WHO multi-country study on women's health and domestic violence. Lancet 2006;368:1260-9.

39. Rahman A. Maternal depression and child health: the need for holistic health policies in developing countries. Harvard Health Policy Rev 2005;6:70-80.

40. Patel V, Rahman A, Jacob KS, et al. Effect of maternal mental health on infant growth in low income countries: new evidence from South Asia. BMJ 2004; 328:820-3.

41. Farmer P. Pathologies of power: health, human rights, and the new war on the poor Berkeley, CA: University of California Press, 2003

42. Galea S, ed. Macrosocial determinants of population health. New York: Springer, 2007.

43. Heggenhougen $\mathbf{K}$. Are the marginalized the slag-heap of globalization? Disparity, health, and human rights. Health Hum Rights 1999:4:205-13. 